\title{
Urticaria and Anaphylaxis in a Child after Skin Contact of Lentil Soup
}

\author{
Orhan Akpınar $^{1}$ \\ Received: 3 January 2018 / Accepted: 19 March 2018 / Published online: 28 March 2018 \\ (C) Dr. K C Chaudhuri Foundation 2018
}

To the Editor: Lentil allergies result in anaphylaxis and urticaria which may be fatal [1]. We present a case of unusually developed anaphylaxis due to skin contact of lentil soup. A 9$y$-old boy had sudden onset of nausea, vomiting, swelling in eyes and lips and redness and swelling all over the body after taking lentil soup. He received medical aid for anaphylaxis. The prick test was not done in the hospital because even very low test doses could cause anaphylaxis in our patient. After the treatment he was discharged with the recommendation to remove lentil from the diet. He did not eat these foods and was extremely sensitive about the content of ready-made products. So he did not have any more allergic reactions until he was 9$\mathrm{y}$-old. At the age of $9 \mathrm{y}$, at a wedding he had meal without soup because the menu had a lentil soup. But the lentil soup of the person sitting next to him was accidentally spilled on the patient's arm. Just after skin contact with a little amount of lentil soup he suffered from itching, redness and swelling of the skin. He received medical aid for anaphylaxis.

Removing lentil and lentil-added products from the diet of children with lentil allergy is a very important measure, but it does not fully protect patients from allergic reactions. In a kitchen cooked with lentils, steam inhalation $[2,3]$ and skin contact, such as in our case, can lead to anaphylaxis. There is no report of anaphylaxis after skin contact of other food items. But local reactions were only developed in the skin contact area $[4,5]$.

\section{Orhan Akpinar}

orhanakpnr@hotmail.com

1 Instutute of Health Sciences, Medical Microbiology Department, Suleyman Demirel University, 32260 Isparta, Turkey
To our knowledge, our report is the first case of hypersensitivity to lentils by skin contact described in literatüre. Our case underlined that a diet of exclusion does not absolutely protects patients from allergic reactions, that can develop also after their skin contact. This risk, even if rare, should be taken under consideration in cases when a child shows an allergic reaction to a particular food. In children with allergies, these conditions must be taken into account and precautions should be taken accordingly.

Acknowledgements The author acknowledges help of Dr. Mehmet Topal, Chairman of the Isparta Children's Hospital.

\section{Compliance with Ethical Standards}

Conflict of Interest None.

\section{References}

1. Kalogeromitros D, Armenaka M, Galatas I, Capellou O, Katsarou A. Anaphylaxis induced by lentils. Ann Allergy Asthma Immunol. 1996;77:480-2.

2. Vitaliti G, Morselli I, Di Stefano V, Lanzafame A, La Rosa M, Leonardi S. Urticaria and anaphylaxis in a child after inhalation of lentils vapours: a case report and literature review. Ital J Pediatr. 2012;38:71.

3. Aysenur K, Akan A, Mustafa E, Müge T, Kocabas CN. Anaphylaxis induced by lentil inhalation. Asian Pac J Allergy Immunol. 2012;30: 167-9.

4. Simonte SJ, Ma S, Mofidi S, Sicherer SH. Relevance of casual contact with peanut butter in children with peanut allergy. J Allergy Clin Immunol. 2003;112:180-2.

5. Tan BM, Sher MR, Good RA, Bahna SL. Severe food allergies by skin contact. Ann Allergy Asthma Immunol. 2001;86:583-6. 